\title{
Effect of vascular endothelial growth factor receptor 2 antagonism on adiposity in obese mice
}

\author{
H Roger Lijnen and Ilse Scroyen \\ Department of Cardiovascular Sciences, Center for Molecular and Vascular Biology, KU Leuven, Campus \\ Gasthuisberg, Onderwijs \& Navorsing 1, Herestraat 49, Box 911, B-3000 Leuven, Belgium
}

Correspondence should be addressed to H R Lijnen Email roger.lijnen@med.kuleuven.be

\begin{abstract}
Development and maintenance of fat depots require angiogenesis, in which vascular endothelial growth factor (VEGF) and its receptors play a crucial role. We have evaluated the effect of blocking VEGF receptor 2 (VEGF-R2) with a MAB (DC101) on adipose tissue of mice with established obesity. Therefore, obese male wild-type C57B1/6 mice were treated with i.p. injection of DC101 (40 mg/kg body weight, twice weekly during 13 weeks) or of the control antibody 1 C8. Treatment with DC101 resulted in a slightly lower body weight but had no effect on subcutaneous (SC) or gonadal (GON) white adipose tissue mass, as monitored by MRI. Histochemical analysis of isolated SC and GON fat pads did not reveal significant effects of DC101 treatment on adipocyte or blood vessel size or density. Plasma levels of the liver enzymes aspartate aminotransferase and alanine aminotransferase as well as liver triglyceride levels were significantly decreased following DC101 treatment. Plasma glucose levels were markedly lower upon DC101 treatment, whereas insulin and adiponectin levels were not affected. Furthermore, Akt phosphorylation in adipose tissues was not affected. Thus, in vivo VEGF-R2 blockade in mice with established nutritionally induced obesity did not significantly affect insulin signaling in adipose tissue or adiposity.
\end{abstract}
Key Words
- adipose tissue
- obesity
- angiogenesis
- VEGF
- VEGF receptor
- insulin

\section{Introduction}

Expansion of adipose tissue is linked to the development of its vasculature. Indeed, adipogenesis is tightly associated with angiogenesis, as shown by the findings that adipose tissue explants trigger blood vessel formation (Castellot et al. 1982), whereas in turn adipose tissue endothelial cells promote preadipocyte differentiation (Varzaneh et al. 1994). Furthermore, adipose tissue growth in mice can be impaired with angiogenesis inhibitors (Rupnick et al. 2002).

Many pro- and anti-angiogenic components have been identified in adipose tissue. Vascular endothelial growth factor (VEGF) family members are major pro-angiogenic factors that stimulate proliferation and migration of endothelial cells (Carmeliet et al. 1996). They bind to transmembrane tyrosine kinase receptors (VEGF-R). A previous study has revealed expression of different isoforms of VEGF-A, VEGF-B, and VEGF-C and the receptors VEGF-R1, VEGF-R2, and VEGF-R3 in subcutaneous (SC) and gonadal (GON) adipose tissues of mice (Voros et al. 2005). Furthermore, blockade of VEGF-R2 but not VEGF-R1 in mice was shown to limit diet-induced fat tissue expansion and suggested a role in early phase fat tissue development (Tam et al. 2009). In addition, several studies have suggested a link between the VEGF/VEGF-R2 pathway and insulin sensitivity and glucose tolerance (Elias et al. 2012, Wada et al. 2010).

Published by Bioscientifica Ltd. 


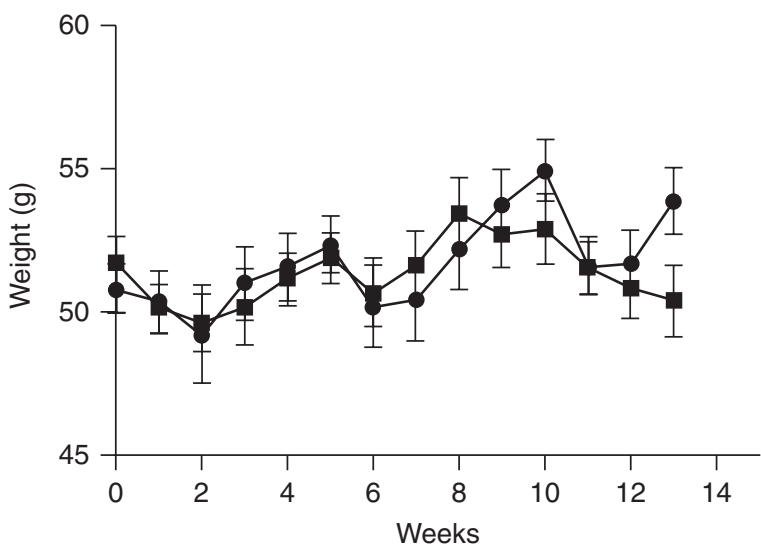

Figure 1

Effect of VEGF-R2 antagonism with DC101 on the evolution of body weight of obese mice. Data are means \pm s.E.M. of nine animals treated with DC101 (filled square) or of ten animals treated with 1C8 (filled circle).

In this study, we have investigated whether DC101, a VEGF-R2 blocking MAB (Bocci et al. 2004), has the potential to affect glucose metabolism or adipose tissuerelated angiogenesis and adiposity in mice with established obesity (which would be more clinically relevant).

\section{Materials and methods}

Male wild-type $\mathrm{C} 57 \mathrm{Bl} / 6$ mice were generated in the KU Leuven animal facility. Five-week-old mice were kept in individual microisolation cages on a $12 \mathrm{~h}$ light: $12 \mathrm{~h}$ darkness cycle and fed a high-fat diet (HFD, Harlan Teklad, TD88137, Zeist, Netherlands; $42 \% \mathrm{kcal}$ as fat, caloric value $20.1 \mathrm{~kJ} / \mathrm{g}$ ) for 28 weeks. Water was always available ad libitum. Age- and weight-matched mice were then treated with i.p. injection of the VEGF-R2 blocking MAB DC101 or of the control MAB $1 \mathrm{C} 8(40 \mathrm{mg} / \mathrm{kg}$ body weight, twice weekly during 13 weeks). DC101, a rat MAB against mouse VEGF-R2, and 1C8, a mouse MAB against human tissue type plasminogen activator (t-PA) not cross-reacting with mouse t-PA, were kind gifts of ThromboGenics (Leuven, Belgium).

Food intake was measured daily and body weight and temperature at weekly intervals. Physical activity at night was monitored in cages equipped with a turning wheel linked to a computer to register full turns $/ 12 \mathrm{~h}$ (1900-0700 h). MRI to determine body and fat volumes was performed as described elsewhere (Hemmeryck et al. 2010).

At the end of the experiments, after overnight fasting, mice were killed by i.p. injection of $60 \mathrm{mg} / \mathrm{kg}$
Nembutal (Abbott Laboratories). Intra-abdominal (GON) and inguinal SC fat pads were removed and weighed; portions were snap-frozen in liquid nitrogen and fixed in $1 \%$ formaldehyde to prepare paraffin sections $(10 \mu \mathrm{m})$ for histology. Other organs including kidneys, lungs, spleen, pancreas, liver, heart, and brain were also removed and weighed. Liver enzymes were determined with routine clinical assays. Triglyceride levels in liver tissue extracts were measured using the Triglycerides FSkit (DiaSys Diagnostic Systems, Holzheim, Germany). Plasma glucose levels were measured after overnight fasting using Glucocard strips (Menarini Diagnostics, Firenze, Italy); insulin (Mercodia, Uppsala, Sweden) and adiponectin (R\&D Europe, Lille, France) levels were determined using commercial ELISAs.

TaqMan gene expression assays (Life Technologies) were used to analyze the mRNA levels in SC and GON adipose tissues of adiponectin (Mm 00456425_m1) and Glut4 (Slc2a4; Mm 00436615_m1), with $\beta$-actin (Mm 01205647_g1) as housekeeping gene, as described elsewhere (Scroyen et al. 2012). For peroxisome proliferator-activated receptor $\gamma$ (PPAR $\gamma$ ), the following primer and probe set was used: fw, ctgtcggttcagaagtgcct; rev, atctccgccaacagcttctc; probe: cccaaacctgatggcattg tgagaca.

To monitor insulin signaling, analysis of Akt and Phospho (P) Akt in extracts of SC or GON adipose tissues was performed using the primary antibodies Akt or P-Akt (9272 or 9271, Cell Signaling Technology, Danvers, MA, USA), as described (Scroyen et al. 2012). Data are normalized to $\beta$-actin as internal control and expressed as the ratio P-Akt/Akt.

Table 1 Effect of VEGF-R2 antagonism with DC101 on body and organ weight of obese mice. Data are means \pm s.E.M. of $n$ experiments

\begin{tabular}{|c|c|c|}
\hline & DC101 $(n=9)$ & $1 C 8(n=10)$ \\
\hline Body weight start (g) & $52 \pm 0.90$ & $51 \pm 0.80$ \\
\hline Body weight end $(\mathrm{g})$ & $50 \pm 1.2 *$ & $54 \pm 1.2$ \\
\hline SC fat (mg) & $2456 \pm 139$ & $2579 \pm 101$ \\
\hline GON fat (mg) & $2311 \pm 91$ & $2408 \pm 157$ \\
\hline Liver (mg) & $2751 \pm 267^{\dagger}$ & $4155 \pm 142$ \\
\hline Spleen (mg) & $307 \pm 19^{\dagger}$ & $164 \pm 8.3$ \\
\hline Kidney (mg) & $293 \pm 8.1$ & $263 \pm 6.2$ \\
\hline Pancreas (mg) & $374 \pm 11$ & $398 \pm 11$ \\
\hline Lungs (mg) & $251 \pm 19$ & $209 \pm 6.2$ \\
\hline Heart (mg) & $216 \pm 9.0$ & $185 \pm 3.4$ \\
\hline Brain (mg) & $67 \pm 2.8$ & $67 \pm 2.5$ \\
\hline
\end{tabular}

${ }^{*} P<0.05$ and ${ }^{\dagger} P \leq 0.001$ vs control. 
Table 2 Effect of VEGF-R2 antagonism with DC101 on body and fat composition of obese mice, as monitored by MRI. Data are means \pm s.E.M. of four determinations in each group

\begin{tabular}{|c|c|c|}
\hline & DC101 & $1 C 8$ \\
\hline Total body volume (ml) & $83 \pm 1.9$ & $81 \pm 1.7$ \\
\hline Abdomen volume $(\mathrm{ml})$ & $27 \pm 0.96$ & $25 \pm 2.7$ \\
\hline Total fat volume (ml) & $41 \pm 2.2$ & $36 \pm 1.6$ \\
\hline Total body fat (\%) & $49 \pm 1.7$ & $44 \pm 1.2$ \\
\hline Visceral fat volume (ml) & $12 \pm 0.87$ & $11 \pm 0.05$ \\
\hline SC fat volume $(\mathrm{ml})$ & $28 \pm 2.9$ & $27 \pm 0.76$ \\
\hline
\end{tabular}

The size and density of adipocytes or blood vessels in the adipose tissues were determined by staining (not shown) with hematoxylin/eosin or with the Bandeiraea simplicifolia lectin (Sigma-Aldrich), a pan marker for rodent endothelial cells (Laitinen 1987), followed by signal amplification with the Tyramide Signal Amplification Cyanine System (Perkin Elmer, Boston, MA, USA). Images were quantitatively analyzed by computer-assisted image analysis, as described (Van Hul et al. 2012a).

All animal experiments were approved by the KU Leuven ethics committee and performed in accordance with the NIH Guide for the Care and Use of Laboratory Animals (1996).

Statistical significance between groups was evaluated by nonparametric Mann-Whitney $U$ test. Values of $P<0.05$ are considered statistically significant.

\section{Results}

After 13 weeks of administration of the anti-VEGF-R2 MAB DC101 $(n=9)$ or of the control MAB 1C8 $(n=10)$ to obese age- and weight-adjusted mice, body weight was slightly lower in the DC101 group $(50 \pm 1.2$ vs $54 \pm 1.2 \mathrm{~g} ; P<0.05)$. Evolution of the body weight over time is shown in Fig. 1. The slight drops in body weight at weeks 2 and 6 are due to overnight fasting before blood sampling for glucose measurements. Food intake $(3.6 \pm 0.1$ vs $3.7 \pm 0.1 \mathrm{~g} /$ day $)$, body temperature $\left(35.0 \pm 0.22\right.$ vs $\left.35.3 \pm 0.26^{\circ} \mathrm{C}\right)$, and physical activity $(1170 \pm 210$ vs $1580 \pm 275$ turns/ $12 \mathrm{~h})$ were comparable for DC101 and 1C8 treatment respectively. Analysis of whole blood cell counts for mice treated with DC101 or 1 C8 revealed a similar contribution of lymphocytes $(54 \pm 4.3$ vs $50 \pm 2.4 \%)$, neutrophils $(29 \pm 3.2$ vs $32 \pm 2.6 \%)$, and monocytes $(10 \pm 1.2 \%$ both). Also platelet counts were not significantly different for DC101 and 1 C8 treatment $\left(1010 \pm 143\right.$ vs $\left.1290 \pm 78 \times 10^{3} / \mu \mathrm{l}\right)$.

The weight of isolated SC and GON adipose tissues was also comparable for both groups, as was the weight of other main organs, with the exception of lower liver and higher spleen weight in the mice treated with DC101 (Table 1). Noninvasive MRI at the end of the experiment did not reveal significant differences in body or fat (total, visceral, or SC) volumes (Table 2). Histochemical analysis of SC and GON adipose tissues did not reveal significant effects of DC101 treatment on adipocyte or blood vessel size or density (Fig. 2 and Table 3).

Plasma total cholesterol and HDL-cholesterol levels at the end of the experiment were significantly lower for DC101 versus 1C8 treatment, whereas triglyceride levels were higher (Table 4). During treatment with 1C8, glucose levels significantly increased whereas they decreased during DC101 treatment, resulting in lower levels at the end of DC101 treatment. Insulin levels were not affected by either treatment, whereas adiponectin levels increased to the same extent during both treatments.
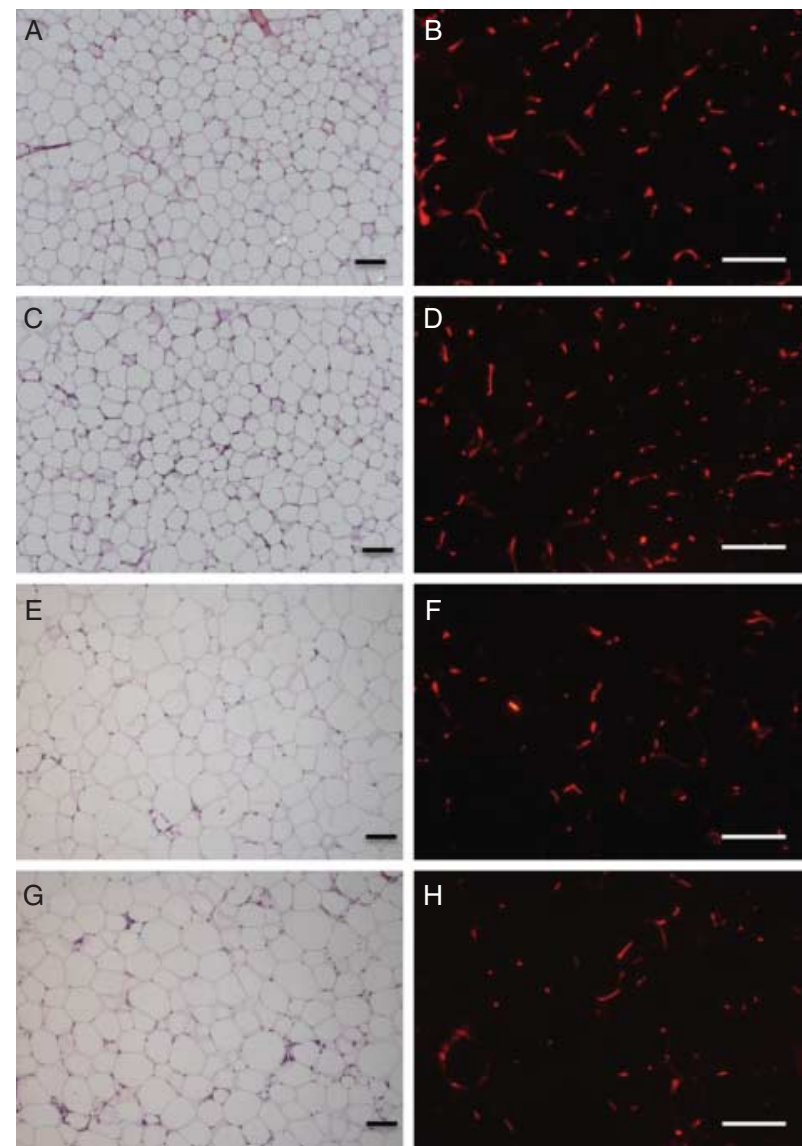

\section{Figure 2}

Histological staining with hematoxylin/eosin (left panels) or Bandeiraea simplicifolia lectin (right panels) of subcutaneous (A, B, C and D) and gonadal $(E, F, G$ and $H$ ) adipose tissues of mice treated with DC101 $(A, B, E$ and $F)$ or $1 C 8(C, D, G$ and $H)$. The scale bars correspond to $100 \mu \mathrm{m}$.

Published by Bioscientifica Ltd. 
Table 3 Effect of VEGF-R2 antagonism with DC101 on adipocyte and blood vessel size and density of obese mice. Data are means \pm s.E.M. of eight to ten determinations

\begin{tabular}{|c|c|c|}
\hline & DC101 & $1 C 8$ \\
\hline \multicolumn{3}{|c|}{ Adipocyte size $\left(\mu \mathrm{m}^{2}\right)$} \\
\hline SC fat & $4064 \pm 92$ & $3648 \pm 131$ \\
\hline GON fat & $5621 \pm 377$ & $5842 \pm 291$ \\
\hline \multicolumn{3}{|c|}{ Adipocyte density $\left(\times 10^{-6} / \mu \mathrm{m}^{2}\right)$} \\
\hline SC fat & $250 \pm 5.2$ & $283 \pm 10$ \\
\hline GON fat & $185 \pm 12$ & $172 \pm 12$ \\
\hline \multicolumn{3}{|c|}{ Blood vessel size $\left(\mu \mathrm{m}^{2}\right)$} \\
\hline SC fat & $43 \pm 2.3$ & $40 \pm 1.8$ \\
\hline GON fat & $42 \pm 1.8$ & $38 \pm 2.7$ \\
\hline \multicolumn{3}{|c|}{ Blood vessel density $\left(\times 10^{-6} / \mu \mathrm{m}^{2}\right)$} \\
\hline $\begin{array}{l}\text { SC fat } \\
\text { GON fat }\end{array}$ & $\begin{array}{l}310 \pm 12 \\
195+15\end{array}$ & $\begin{array}{l}342 \pm 13 \\
210+19\end{array}$ \\
\hline GON fat & $195 \pm 15$ & $210 \pm 19$ \\
\hline
\end{tabular}

Determination of liver enzymes revealed a significant decrease during DC101 treatment of aspartate aminotransferase (AST) and alanine aminotransferase (ALT); during 1C8 treatment, such differences were not observed, resulting in lower AST and ALT levels at the end of DC101 treatment. Levels of alkaline phosphatases were not affected by DC101 treatment but decreased during 1C8 treatment. Plasma triglyceride levels decreased upon administration of DC101 and 1C8 but were higher at the end of DC101 treatment (Table 4). In liver tissue extracts, triglyceride levels were significantly lower for DC101-treated mice $(29 \pm 5.7$ vs $70 \pm 3.3 \mathrm{mg} / \mathrm{g}$ tissue for $1 \mathrm{C} 8$ treatment; $P<0.0001)$. Total protein content in the liver extracts was comparable for DC101 and 1C8 treatment ( $13 \pm 0.42$ vs $13 \pm 0.55 \mathrm{mg} / \mathrm{g}$ tissue).

In SC or GON adipose tissues, no significant differences were observed in the expression of Ppary (Pparg), adiponectin, or Glut4 between treatment with DC101 or 1C8 (Fig. 3A, B and C). Furthermore, the ratio of P-Akt/Akt was similar in SC and GON adipose tissues for both treatments (Fig. 3D).

\section{Discussion}

Inhibition of angiogenesis may be a potential strategy to affect adipose tissue development (Rupnick et al. 2002). Furthermore, the VEGF/VEGF-R system may play a role in insulin resistance (Elias et al. 2012). In this study, we have evaluated whether VEGF-R2 blockade affects adipose tissue-related angiogenesis and fat mass or insulin signaling in mice with established nutritionally induced obesity. Using the same model, we have previously shown that matrix metalloproteinase inhibitors, such as Tolylsam and ABT-518, have the potential to impair adipose tissue angiogenesis and development (Van Hul et al. 2012a,b). In this study, we have used the rat MAB DC101 that was previously shown to efficiently inhibit tumor angiogenesis in mouse models, using similar administration schemes for shorter duration (Prewett et al. 1999, Kadambi et al. 2001, Fischer et al. 2007). In addition, at a dose of $25 \mathrm{mg} / \mathrm{kg}$ i.p. given every 2 days, DC101 significantly impaired postnatal retinal or systemic vascular development (Van de Veire et al. 2010). In our study, DC101 at a dose of $40 \mathrm{mg} / \mathrm{kg}$ i.p. twice weekly did not, however, affect adipose tissue-related angiogenesis nor did fat mass in obese mice. A limitation of our study may be that we have not directly demonstrated in vivo blockade of VEGF-R2. The total body weight of the mice in our study was somewhat reduced compared with controls;

Table 4 Effect of VEGF-R2 antagonism with DC101 on metabolic parameters and liver enzymes in plasma of obese mice. Data are means \pm s.E.M. of nine to ten determinations

\begin{tabular}{|c|c|c|c|c|}
\hline & \multicolumn{2}{|c|}{ DC101 } & \multicolumn{2}{|c|}{$1 \mathrm{C8}$} \\
\hline & Start & End & Start & End \\
\hline Glucose (mg/dl) & $127 \pm 12$ & $112 \pm 15^{\dagger}$ & $129 \pm 7$ & $169 \pm 7.3^{11}$ \\
\hline Insulin (ng/ml) & $0.81 \pm 0.19$ & $1.08 \pm 0.14$ & $0.80 \pm 0.23$ & $0.95 \pm 0.07$ \\
\hline Adiponectin $(\mu \mathrm{g} / \mathrm{ml})$ & $7.6 \pm 1.1$ & $12 \pm 0.82$ & $7.3 \pm 0.48$ & $12 \pm 0.98$ \\
\hline Total cholesterol (mg/dl) & $440 \pm 17$ & $187 \pm 19^{\ddagger, \|}$ & $478 \pm 19$ & $320 \pm 11^{11}$ \\
\hline HDL-cholesterol (mg/dl) & $181 \pm 26$ & $133 \pm 13^{\ddagger}$ & $252 \pm 9$ & $234 \pm 5$ \\
\hline LDL-cholesterol (mg/dl) & $239 \pm 19$ & $40 \pm 9$ & $205 \pm 14$ & $76 \pm 8^{\| 1}$ \\
\hline Triglycerides (mg/dl) & $100 \pm 9$ & $76 \pm 9 *, \S$ & $108 \pm 7$ & $51 \pm 4^{\|}$ \\
\hline Alkaline phosphatases (U/l) & $186 \pm 10$ & $133 \pm 25$ & $193 \pm 12$ & $116 \pm 11$ \\
\hline AST $(\mathrm{U} / \mathrm{l})$ & $442 \pm 27$ & $279 \pm 25^{\S}$ & $478 \pm 36$ & $438 \pm 59$ \\
\hline $\mathrm{ALT}(\mathrm{U} / \mathrm{I})$ & $513 \pm 45$ & $146 \pm 24^{\dagger, \|}$ & $510 \pm 39$ & $360 \pm 48$ \\
\hline
\end{tabular}

AST, aspartate aminotransferase; ALT, alanine aminotransferase. ${ }^{*} P<0.05,{ }^{\dagger} P<0.005$, and ${ }^{\ddagger} P<0.0005$ vs end of 1 C 8 treatment. ${ }^{\S} P<0.05$ and $" P<0.0005$ vs start of the same treatment.

http://jme.endocrinology-journals.org DOI: 10.1530/JME-12-0244
(C) 2013 Society for Endocrinology Printed in Great Britain
Published by Bioscientifica Ltd. 

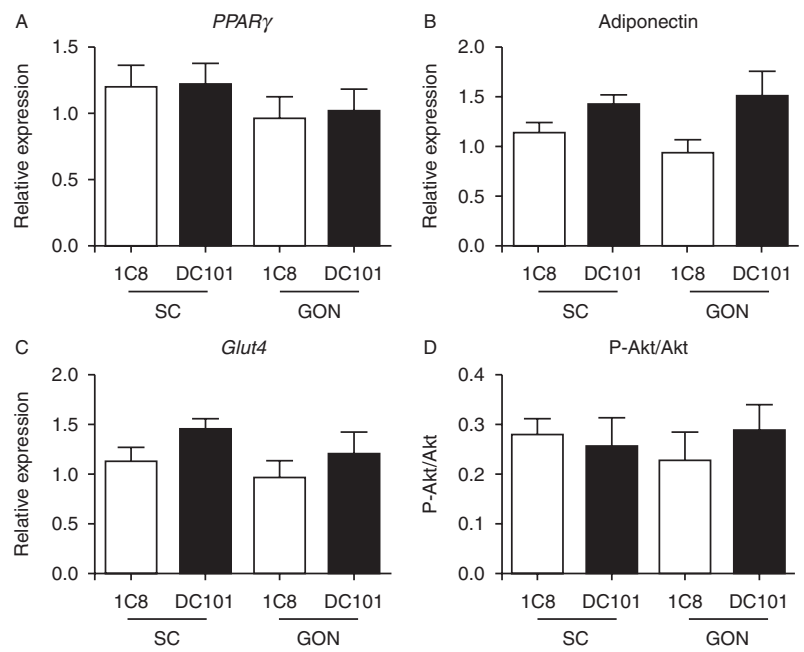

Figure 3

Monitoring of insulin signaling pathways in SC or GON adipose tissues of mice treated with 1C8 (open bars) or DC101 (filled bars). Relative gene expression as determined by quantitative RT-PCR is shown for Ppary (A), adiponectin (B), and Glut4 (C). Data are means \pm s.E.M. of seven or eight determinations. (D) Shows the ratio of P-Akt/Akt as determined by western blotting of protein extracts prepared from SC or GON adipose tissues. Data are means \pm S.E.M. of four determinations.

Sun et al. (2012) also recently showed that VEGF-A/VEGF$\mathrm{R} 2$ blockade in genetic obese $o b / o b$ mice leads to reduced body weight gain. The similar distribution of white blood cells suggests that the rat antibody DC101 and the mouse antibody 1C8 did not elicit a markedly different immune response.

In a previous study, treatment of $\mathrm{C} 57 \mathrm{Bl} / 6$ mice with DC101 (40 mg/kg every 3 days) had no effect on body weight during the first 5-6 weeks of HFD feeding, but afterwards (weeks 6-13), the rate of weight gain decreased significantly compared with the HFD controls (Tam et al. 2009). This was associated with a significantly decreased food intake in the DC101 group that was apparently not observed in the first 5-6 weeks. We did not observe a difference in food intake over the 13-week experimental period, and the evolution of body weight was similar to that in the control group. The main differences with our study are the start age ( 12 vs 33 weeks in our study) and the start weight (lean vs obese).

The data of Tam et al. (2009) thus suggest that blocking VEGF-R2-mediated angiogenesis may be effective during stages of active fat expansion. Furthermore, studies with low-molecular-weight tyrosine kinase inhibitors, such as SU5416, which selectively inhibit VEGF-R2, showed accumulation of active compound in adipose tissue, and efficient inhibition of angiogenesis in a rat aortic ring model (Rasmussen et al. 2011) as well as in a mouse corneal neovascularization model (Keskin et al. 2012). The VEGF/VEGF-R2 pathway may also be important for angiogenesis during de novo adipose tissue formation from preadipocytes (Fukumura et al. 2003). By contrast, our study in obese mice indicates that antiVEGF-R2 treatment did not affect established blood vessels and did not induce regression of fat mass.

DC101 treatment was associated with reduced liver weight in the obese mice, and with markedly lower levels of the liver enzymes AST and ALT compared with treatment with 1C8. Furthermore, liver triglyceride content was significantly reduced, suggesting reduced liver steatosis. Triglyceride levels indeed were previously reported to be indicative for liver steatosis (Donato \& Gomez-Lechon 2012), although this was not histologically confirmed in this study. Furthermore, at the end of the experiment, plasma cholesterol and glucose levels were significantly lower for DC101 treatment compared with 1C8. It is conceivable that VEGF/VEGF-R2 blockade and associated higher circulating VEGF levels in this model result in an improvement in glucose metabolism and in insulin signaling, as previously observed with $o b / o b$ mice (Sun et al. 2012). Furthermore, it was recently shown that overexpression of VEGF in the mouse was associated with improved whole body insulin sensitivity and glucose tolerance (Elias et al. 2012). It was also reported that soluble VEGF-R2 is increased in sera of subjects with metabolic syndrome and insulin resistance (Wada et al. 2012). These studies thus support a link between the VEGF/VEGF-R2 pathway and insulin sensitivity. In our study in obese mice, however, we did not observe effects of DC101 treatment on plasma levels of insulin or adiponectin, nor on adipose tissue gene expression of Ppary, adiponectin, or of the insulin-responsive glucose transporter Glut4. Furthermore, a similar ratio of P-Akt/Akt in adipose tissues of mice treated with DC101 or 1C8 does not support an effect on insulin signaling in the obese mice.

Thus, whereas the VEGF/VEGF-R2 pathway has been shown to play an important role in angiogenesis during early phases of adipose tissue formation, we did not observe marked effects of VEGF-R2 antagonism on nutritionally induced established obesity. This antiangiogenic approach thus does not have the potential to affect obese fat mass that developed during prolonged high-fat intake and does not result in improved insulin sensitivity.

Published by Bioscientifica Ltd. 


\section{Declaration of interest}

The authors declare that there is no conflict of interest that could be perceived as prejudicing the impartiality of the research reported.

\section{Funding}

The Center for Molecular and Vascular Biology is supported by the 'Programmafinanciering KU Leuven' (PF10/014).

\section{Author contribution statement}

H R L contributed in the design and analysis of the study and writing of manuscript. I $\mathrm{S}$ was involved in analysis of samples and data acquisition.

\section{Acknowledgements}

Skillful technical assistance by L Frederix, C Vranckx, and A De Wolf is gratefully acknowledged.

\section{References}

Bocci G, Danesi R, Marangoni G, Fioravanti A, Boggi U, Esposito I, Fasciani A, Boschi E, Campani D, Bevilacqua G et al. 2004 Antiangiogenic versus cytotoxic therapeutic approaches to human pancreas cancer: an experimental study with a vascular endothelial growth factor receptor-2 tyrosine kinase inhibitor and gemcitabine. European Journal of Pharmacology 498 9-18. (doi:10.1016/j.ejphar.2004.07.062)

Carmeliet P, Ferreira V, Breier G, Pollefeyt S, Kieckens L, Gertsenstein M, Fahrig M, Vandenhoeck A, Harpal K, Eberhardt C et al. 1996 Abnormal blood vessel development and lethality in embryos lacking a single VEGF allele. Nature 380 435-439. (doi:10.1038/380435a0)

Castellot JJ Jr, Karnovsky MJ \& Spiegelman BM 1982 Differentiationdependent stimulation of neovascularization and endothelial cell chemotaxis by 3 T3 adipocytes. PNAS 79 5597-5601. (doi:10.1073/ pnas.79.18.5597)

Donato MT \& Gomez-Lechon MJ 2012 Drug-induced liver steatosis and phospholipidosis: cell-based assays for early screening of drug candidates. Current Drug Metabolism 13 1160-1173. (doi:10.2174/ $138920012802850001)$

Elias I, Franckhauser S, Ferré T, Vilà L, Tafuro S, Muñoz S, Roca C, Ramos D, Pujol A, Riu E et al. 2012 Adipose tissue overexpression of vascular endothelial growth factor protects against diet-induced obesity and insulin resistance. Diabetes 61 1801-1813. (doi:10.2337/db11-0832)

Fischer C, Jonckx B, Mazzone M, Zacchigna S, Loges S, Pattarini L, Chorianopoulos E, Liesenborghs L, Koch M, De Mol M et al. 2007 Anti-PIGF inhibits growth of VEGF(R)-inhibitor-resistant tumors without affecting healthy vessels. Cell 131 463-475. (doi:10.1016/ j.cell.2007.08.038)

Fukumura D, Ushiyama A, Duda DG, Xu L, Tam J, Krishna V, Chatterjee K, Garkavstev I \& Jain RK 2003 Paracrine regulation of angiogenesis and adipocyte differentiation during in vivo adipogenesis. Circulation Research 93 88-97. (doi:10.1161/01.RES.0000099243.20096.FA)

Hemmeryck B, Loeckx D, Dresselaers T, Himmelreich U, Hoylaerts M \& Lijnen HR 2010 Age-associated adaptations in murine adipose tissues. Endocrine Journal 57 927-932.
Kadambi A, Mouta Carreira C, Yun CO, Padera TP, Dolmans DE, Carmeliet P, Fukumura D \& Jain RK 2001 Vascular endothelial growth factor (VEGF)-C differentially affects tumor vascular function and leukocyte recruitment: role of VEGF-receptor 2 and host VEGF-A. Cancer Research 61 2404-2408.

Keskin U, Totan Y, Karadağ R, Erdurmus M \& Aydin B 2012 Inhibitory effects of SU5416, a selective vascular endothelial growth factor receptor tyrosine kinase inhibitor, on experimental corneal neovascularization. Ophthalmic Research 47 13-18. (doi:10.1159/000324994)

Laitinen L 1987 Griffonia simplicifolia lectins bind specifically to endothelial cells and some epithelial cells in mouse tissue. Histochemical Journal 19 225-234. (doi:10.1007/BF01680633)

Prewett M, Huber J, Li Y, Santiago A, O'Connor W, King K, Overholser J, Hooper A, Pytowski B, Witte L et al. 1999 Antivascular endothelial growth factor receptor (fetal liver kinase 1) monoclonal antibody inhibits tumor angiogenesis and growth of several mouse and human tumors. Cancer Research 59 5209-5218.

Rasmussen JG, Frøbert O, Pilgaard L, Kastrup J, Simonson U, Zachar V \& Fink T 2011 Prolonged hypoxic culture and trypsinization increase the pro-angiogenic potential of human adipose tissue-derived stem cells. Cytotherapy 13 318-328. (doi:10.3109/14653249.2010.506505)

Rupnick MA, Panigrahy D, Zhang CY, Dallabrida SM, Lowell BB, Langer R \& Folkman MJ 2002 Adipose tissue mass can be regulated through the vasculature. PNAS 99 10730-10735. (doi:10.1073/pnas.162349799)

Scroyen I, Frederix L \& Lijnen HR 2012 Axl deficiency does not affect adipogenesis or adipose tissue development. Obesity 20 1168-1173. (doi:10.1038/oby.2011.399)

Sun K, Wernstedt Asterholm I, Kusminski CM, Bueno AC, Wang ZV, Pollard JW, Brekken RA \& Scherer PE 2012 Dichotomous effects of VEGF-A on adipose tissue dysfunction. PNAS 109 5874-5879. (doi:10.1073/pnas.1200447109)

Tam J, Duda DG, Perentes JY, Quadri RS, Fukumura D \& Jain RK 2009 Blockade of VEGFR2 and not VEGF1 can limit diet-induced fat tissue expansion: role of local versus bone marrow-derived endothelial cells. PLOS ONE 4 e4974. (doi:10.1371/journal.pone.0004974)

Van de Veire S, Stalmans I, Heindrycks F, Oura H, Tijeras-Raballand A, Schmidt T, Loges S, Albrecht I, Jonckx B, Vinckier S et al. 2010 Further pharmacological and genetic evidence for the efficacy of PIGF inhibition in cancer and eye disease. Cell 141 178-190. (doi:10.1016/ j.cell.2010.02.039)

Van Hul M, Bauters D, Himmelreich U, Kindt N, Noppen B, Vanhove M \& Lijnen HR 2012a Effect of gelatinase inhibition on adipogenesis and adipose tissue development. Clinical and Experimental Pharmacology \& Physiology 39 49-56. (doi:10.1111/j.1440-1681.2011.05635.x)

Van Hul M, Lupu F, Dresselaers T, Buyse J \& Lijnen HR 2012b Matrix metalloproteinase inhibition affects adipose tissue mass in obese mice. Clinical and Experimental Pharmacology \& Physiology 39 544-550. (doi:10.1111/j.1440-1681.2012.05714.x)

Varzaneh FE, Shillabeer G, Wong KL \& Lau DC 1994 Extracellular matrix components secreted by microvascular endothelial cells stimulate preadipocyte differentiation in vitro. Metabolism 43 906-912. (doi:10.1016/0026-0495(94)90275-5)

Voros G, Maquoi E, Demeulemeester D, Clerx N, Collen D \& Lijnen R 2005 Modulation of angiogenesis during adipose tissue development in murine models of obesity. Endocrinology 146 4545-4554. (doi:10.1210/ en.2005-0532)

Wada H, Satoh H, Kitaoka S, Ono K, Morimoto T, Kawamura T, Nakano T, Fujita M, Kita T, Shimatsu A et al. 2010 Soluble VEGF receptor-2 is increased in sera of subjects with metabolic syndrome in association with insulin resistance. Atherosclerosis 208 512-517. (doi:10.1016/ j.atherosclerosis.2009.07.045)

Received in final form 12 February 2013

Accepted 19 February 2013

Accepted Preprint published online 20 February 2013 http://jme.endocrinology-journals.org DOI: 10.1530/JME-12-0244
(C) 2013 Society for Endocrinology Printed in Great Britain 